\title{
ESCOLA: ESPAÇO PARA A PRODUÇÃO DE CONHECIMENTO
}

\section{As transformações nas formas de perceber e apreender a realidade, facultadas pelas tecnologias da comunicação, precisam chegar à escola}

A palavra escola em grego significa o lugar do ócio. Na Idade Média, surge para atender à demanda de uma nova classe social que não precisava trabalhar para garantir a sua sobrevivência, mas que necessitava ocupar o seu tempo ocioso de forma nobre e digna. Este lugar era a escola que, inicialmente, se instaura como um espaço para o lazer e, conseqüentemente, para o prazer. Com o passar do tempo, começa a perder esse significado, passando a ser vista como um lugar onde se vai buscar $e$ adquirir novas informações, na maioria das vezes de forma descontextualizada, tornandose um lugar enfadonho e desprazeiroso ${ }^{1}$. Atualmente, tal afirmativa, pode ser ratificada no discurso de crianças, adolescentes e até mesmo dos adultos que necessitam ir à escola, marcando a diferença entre o aprender com prazer fora da escola e o aprender dentro do espaço escolar.

A repressão simbólica é tão violenta que, às vezes, não percebemos que estamos internalizando um discurso que só dá valor às aprendizagens realizadas dentro da escola. Tudo o que é aprendido fora é visto com reserva, com desconfiança. Essa visão marca a diferença entre a aprendizagem sistemática e a aprendizagem assistemática que se constrói no cotidiano dos atores sociais, a partir da interação com os signos e instrumentos presentes na sociedade. Instrumento aqui compreendido na perspectiva vygotskiana, como elemento mediador entre o sujeito e o objeto do conhecimento. Como diz Vygotsky, "o uso de meios artificiais - a transição para a atividade mediada - muda, fundamentalmente, todas as operações psicológicas, assim como o uso de instrumentos amplia de forma ilimitada a gama de atividades em cujo interior as novas funções psicológicas podem operar"2 2 .

Nos dias atuais percebemos a presença intensa de instrumentos tecnológicos - os quais preferimos denominar de elementos tecnológicos para diferenciá-los de uma perspectiva instrumental e mecanicista -, que vêm possibilitando uma nova razão cognitiva, um novo pensar, novos caminhos para construir o conhecimento de forma prazerosa e lúdica. Tal

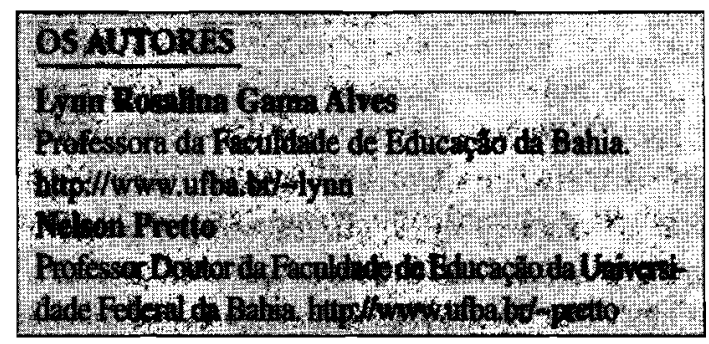

1. Segundo Dermeval Saviani, esta forma de educação surgiu com o advento da industrialização e a ascensão da burguesia. Trata-se da formação "escolar", considerada o ulterior desenvolvimento da Educação. SAVIANI, Dermeval. Pedagogia histórico-crítica: primeiras aproximações. São Paulo: Cortez, Autores Associados, 1991.

2. VYGOTSKY, Lev Semyonovitch. A formação social da mente: o desenvolvimento dos processos psicológicos superiores. São Paulo: Martins Fontes, 1994. p. 73. 
constatação provoca muitos questionamentos por parte de vários segmentos da sociedade, inclusive dos professores, que vêem, de um lado, essas tecnologias com certa desconfiança e, de outro, com expectativas exageradas que fogem à realidade, uma vez que acreditam que estes elementos tecnológicos, por si só, possam resolver os problemas do sistema educacional. Vivemos numa oscilação constante entre esses pólos e pensamos ser urgente a construção de uma postura de equilíbrio, percebendo as possibilidades e limites dessas tecnologias no ambiente escolar.

Pierre Lèvy vem denominando esses elementos tecnológicos de tecnologias da inteligência, na medida em que possibilitam uma transformação da ecologia cognitiva. As tecnologias da inteligência "reorganizam, de uma forma ou de outra, a visão de mundo de seus usuários e modificam seus reflexos mentais. (...) $\mathrm{Na}$ medida em que a informatização avança, certas funções são eliminadas, novas habilidades aparecem, a ecologia cognitiva se transforma ${ }^{\prime \prime 3}$.

Arriscamos dizer, portanto, que a interação com os computadores, games, livros, Internet, TV, vídeo representa a possibilidade de alteração das estruturas cognitivas do indivíduo, gerando um desequilíbrio que instaura uma nova forma de pensar.

Nossas crianças e adolescentes vivem nesse mundo high tech (alta tecnologia), construindo e aprendendo novas formas de ser e pensar $^{4}$ que possibilitam o surgimento de uma lógica rizomática ${ }^{5}$. Lógica esta que se constrói a partir da diversidade que permeia o sujeito capaz de conhecer - em permanente processo de construção e desconstrução - e o mergulho dos sujeitos no mundo plural e coletivo da comunicação digital. Como reage a escola frente a esses jovens?

A escola ainda se mantém com a tecnologia low tech (baixa tecnologia), resistindo em atender às novas demandas sociais e cognitivas, e às necessidades desse novo sujeito, em construção. É nesse contexto que as tecnologias da inteligência chegam às escolas, através de projetos políticos ou das pressões do mercado. $\mathrm{O}$ envolvimento dos pesquisadores das universidades e dos profissionais que estão refletindo teoricamente sobre estas questões, por si só, não garante que esses projetos, ao chegarem às escolas públicas, não apareçam como verdadeiros pacotes prontos, sem muitas possibilidades de transformação.

A história da presença das tecnologias da comunicação e da informação na educação no Brasil possui um percurso que já foi discutido por diversos autores ${ }^{6}$. Na informática educativa, os registros apontam para o Educom - Projeto de Informatização da Educação Brasileira - que, na década de 80 , norteou as experiências nos Estados do Rio Grande do Sul, Pernambuco, Minas Gerais, Rio de Janeiro e na cidade de Campinas, SP; para o ProninfePrograma Nacional de Informática na Educação ${ }^{7}-\mathrm{e}$, finalmente, para o seu renascimento em 1996, através do Proinfo - Programa de Informática na Educação. No campo da comu-

3. LÈVY, Pierre. As tecnologias da inteligência. O futuro do pensamento na era da informática. Rio de Janeiro: Editora 34, 1993. p. 54. 4. Ver sobre o assunto das novas sensibilidades artigo de: MARTÍN-BARBERO, Jesús. Cidade virtual: novos cenários da comunicação. Comunicação \& Educação. São Paulo: CCA-ECA-USP/Moderna, n.11, jan./abr. 1998. p. 53-67. (N.Ed.)

5. DELEUZE G., GUATARRI, F. Rizoma. Parma-Lucca: Pratiche Editrice, 1977.

LÈVY, Pierte. As tecnologias... op. cit.

6. Alguns destaques: Laymert Garciá dos Santos, Helena M. B. Boemy, Maria Luiza Belloni, Marília Franco, Maria Cândida Moraes, Mariza Lucena, Paulo Cysneiros, Léa Fagundes, Margarida M. K. Kunsch, entre tantos outros.

7. Para maiores informaçōes ver artigo de MORAES, Maria C. Informática educativa no Brasil: um pouco de história. Em Aberto. Brasília, ano 12, n. 57 , jan./mar. 1993. 
nicação, especialmente da televisão e do vídeo, temos preocupações semelhantes desde o nascimento das televisões educativas, quase coincidindo com o próprio nascimento da televisão no Brasil. No final da década de 60 , dá-se início a um dos projetos pioneiros na área, o Projeto Saci ${ }^{8}$, implantado no Rio Grande do Norte. Nascem as televisões educativas do Maranhão, Ceará e Amazonas. Surgem projetos privados como o Vídeo Escola da Fundação Roberto Marinho e o Canal Futura, também liderado por esta Fundação, agora com o envolvimento de grandes organizações brasileiras como a Fundação Odebrecht, o Instituto Ayrton Senna, a Fundação Bradesco. O setor público está presente de forma intensa na área, através da $T V$ Escola, canal educativo que é um dos pilares básicos da política do Ministério da Educação e Cultura na relação educação/tecnologia. Este percurso, no entanto, não garantiu - e ainda não garante - uma forte participação da comunidade escolar no processo.

\section{TECNOLOGIA A SERVIÇO DO SABER}

Como os professores, alunos, diretores, corpo técnico pedagógico podem levar adiante as diretrizes norteadoras destas ações, se muitas vezes não compreendem o porquê, para quê e como interagir com esses elementos tecnológicos na escola? Em outras palavras, a não-percepção clara das razões mais profundas desta relação educação/tecnologia fez com que, muitas vezes, esses equipamentos fossem subutilizados, sendo quase mais um elemento de decoração ou de uso promocional da instituição escolar, tendo pouco uso e tornando-se rapidamente obsoletos.
As difículdades de uma incorporação diferenciada dessas tecnologias são evidentes. São inúmeras as tentativas, mas o que percebemos é que a escola continua a negar o conhecimento que os jovens constroem a partir das interações que eles estabelecem com essas tecnologias. A escola educa e o faz muito bem, pois induz os jovens a uma repetição quase automática do discurso reprodutivista dos adultos, os quais negam esses novos caminhos no processo de construção do conhecimento, mantendo a dicotomia maniqueísta entre o saber escolarizado e o não-escolarizado.

O Núcleo Educação e Comunicação, da Faculdade de Educação da Universidade Federal da Bahia, vem estudando esta problemática. Promoveu, em agosto de 1997, com o objetivo de investigar o que pensam as crianças e os adolescentes sobre a relação educação/tecnologia, um inusitado encontro de crianças e adolescentes para "criar um espaço dialógico, aberto e confortável, onde as crianças pudessem se expressar espontaneamente sobre a sua relação com as máquinas de um modo geral - rádio, TV, vídeo, games, computadores, Internet --, a fim de que, com o poder de uso das diversas linguagens, usufruíssem publicamente deste direito"9.

Reuniram-se crianças e adolescentes na faixa etária dos 5 a 15 anos, que estavam dentro ou fora da escola, com experiências bem diversificadas em torno das novas tecnologias, com o objetivo de propiciar aos adultos experiência útil, que servisse para reflexão dos futuros professores desta meninada. Para uma maior compreensão da proposta e do seu desdobramento, faz-se necessário um breve comentário sobre os atores desse processo.

\footnotetext{
8. O Projeto Saci, implantado pelo governo brasileiro com assessoria de técnicos americanos. entre 1967 e 1974, tentou, através do uso da televisão, formar professores leigos no Nordeste do país. Ver mais sobre o uso de tecnologia na educação em: Comunicação \& Educação, n. 2, 3, 4, 5, 6 e 9. São Paulo: CCA-ECA-USP/Moderna. (N.Ed.)

9. UFBA/Faculdade de Educação. Crianças, TVs, games, vídeos, computadores... E a escola? Primeiro eles! Conversando com crianças. Salvador-BA, FACED: Núcleo de Educação e Comunicação da UFBA, 1997. p. 3. [URL= http://www.faced.ufba.br/ redcom/eventos/games.htm]. Como parte da pesquisa foi produzido um vídeo sobre o tema.
} 


\section{PERFIL DAS CRIANÇAS}

Claudemir dos Santos Júnior, 13 anos, cursa a sétima série na Escola Municipal Dr. Alexandre Leal Costa e participa de um projeto da Prefeitura Municipal de Salvador, que tem como objetivo conectar as escolas municipais à Internet. Este projeto existe desde julho de 1995 e envolve, atualmente, 17 escolas da rede municipal. Claudemir teve a oportunidade de construir a sua própria homepage [http:// www.faced.ufba.br/ pie] como parte das atividades deste projeto.

Bruna Lima de Souza Santos, 8 anos, está fora da escola e tem 14 irmãos. Ela ajuda na renda familiar através da venda de canetas no posto do Banco do Brasil da Universidade e é conhecida de um bom número de professores e funcionários da UFBA por sua excelente memória.

Gabriel Muricy Dela Plata, 10 anos, cursa a terceira série no Instituto Social da Bahia, escola de classe média em Salvador. Gabriel tem muita intimidade com o computador e o video game. Ele já possui seu próprio e-mail [gabrielmp@hotmail.com].

Indi Nascimento Figueiredo, 8 anos, está na segunda série na Fundação Nossa Senhora de Lourdes (Sacramentinas), em Feira de Santana, Bahia. Esta escola atende basicamente à classe média da região.

Mariane Moreira da Silva, 11 anos, cursa a quarta série na Escola Municipal Beatriz Bispo Miranda, também em Feira de Santana. Sua escola possui apenas um vão medindo aproximadamente $50 \mathrm{~m}^{2}$, com divisórias de madeira, onde são ministradas simultaneamente aulas para todas as séries do ensino fundamental (classe multisseriada).

Júlia Carolina Cerqueira Dias tem 5 anos, já esteve em creches e pré-escola e, no momento, está fora da escola. Adora jogos em computador. Seus pais trabalham com informática.
Osvaldo Pereira da Silva (Ticó), 15 anos, já esteve fora da escola, tendo retornado em 1997. Ticó adora jogos eletrônicos e passa boa parte do seu tempo nas lojas de games do seu bairro, a Boca do Rio, em Salvador, Bahia.

Tatiane de Andrade Matos tem 14 anos e cursa a oitava série na Escola Municipal Dr. Alexandre Leal Costa, também participando do Projeto Internet nas Escolas em Salvador. Tatiane já construiu sua própria homepage [http://www.faced.ufba.br/ pie].

Divonei Rodrigo dos Santos, 10 anos, estuda na Escola Municipal do Calabetão em Salvador, outra escola municipal envolvida com o Projeto Internet. Ele não tem ainda sua homepage, mas foi quem produziu o desenho usado no cartaz de divulgação do evento.

Neste encontro, que assumiu caráter lúdico e descontraído, rompendo com a rígida organização das escolas e universidades, as crianças e adolescentes ficaram sentados em almofadas no chão, em um ambiente especialmente preparado para eles. Nesse auditório existiam câmera de vídeo, televisão, video games, livros, lápis de cera, papéis, jogos, enfim, instrumentos mediadores da relação criança-adulto e do processo de construção do conhecimento.

Apesar da descontração e espontaneidade que norteou o encontro, o discurso do adulto esteve sempre presente na fala dos jovens, que até reconheciam a aprendizagem fora do ambiente escolar, mas atribuíam maior significação ao saber formal, transmitido pelos professores na escola. Indi, ao ser indagada sobre a presença da TV na escola, afirma "... em casa assistimos [a TV] para nos distrair, no colégio para aprender...". Percebe-se claramente que, para ela, o aprender da escola tem uma importância maior. Mais adiante ela vai confirmar a diferença entre aprender e distrair "... porque em casa nos distraímos assim, no modo de se divertir. No colégio distraímos mas aprendemos ao mesmo tempo". 


\section{RESPONSABILIDADE PARA MUDANÇA}

Para Tatiane, a TV na escola possibilitaria uma aprendizagem sem monotonia, "por que melhora nossa aprendizagem. não sofre com monotonia... a professora bota fitas para ficar assistindo, depois discutimos, fazemos depoimentos e assim aprendemos mais". Aqui podemos sinalizar dois importantes aspectos. $\mathrm{O}$ primeiro, a monotonia que vem norteando o processo ensino-aprendizagem. Será que os professores não se dão conta disso? Preferem responsabilizar os jovens pelos fracassos do processo ensino-aprendizagem, atribuindo a eles o fato de não quererem nada, de serem rebeldes, agressivos, enfim uma infinidade de desculpas para justificar o baixo rendimento, a evasão e a indisciplina na escola. Percebemos que estes aspectos, na verdade, são sintomas de que algo não vai bem com a escola e com os professores. O mais interessante, no entanto, é que, quando questionados, muitos professores não se consideraram integrantes do processo e continuam atribuindo ao outro a responsabilidade pelo fato de a escola ter-se tornado um local desprazeroso, monótono e autoritário, uma vez que as hierarquias existentes no sistema educacional impõem um comportamento quase burocrático dos atores deste processo. $\mathrm{Na}$ verdade, nem atores pois, em função dessa burocrática hierarquização, o que vemos é a incorporação de procedimentos e práticas para o cumprimento das leis, personificada nos coordenadores e/ou diretores das escolas, quando não nos currículos e materiais didáticos.

O produto dessa escola é um indivíduo capaz de seguir ordens com atenção, não questionador, capaz de fazer algo sem se preocupar/interrogar por que é feito daquele modo e não de outro, sempre confiante em que al- guém já pensou por ele o modo de fazer; sendo capaz de se esforçar para fazer o melhor em seu posto na linha de montagem. ${ }^{10}$

A lei é necessária para que o indivíduo se estruture como sujeito, mas a partir do momento em que esta lei se apresenta de forma autoritária, punidora e repressora. compromete-se o papel da escola, afastando os alunos da mesma e dos professores. Em última instância, burocratiza-se o ato de aprender.

Estes jovens afirmam que o melhor da escola é o intervalo (recreio), que deveria ter seu tempo ampliado. Eles associam ao intervalo o momento de prazer e troca com os demais colegas e, com isso, entendem este espaço como importante para a socialização. Justamente aquilo que deveria ser o todo da escola: um espaço de socialização prazerosa de conhecimentos e saberes.

Paradoxalmente, é no espaço escolar que encontramos as vozes silenciadas das crianças, dos jovens e adolescentes: negamos suas falas, sua literatura, seus desejos e emoções. suas hipóteses de trabalho, suas crenças e indagações... Esquecemos as culturas dos migrantes e as miscigenações que impregnam nossa brasilidade e nos tornamos indiferentes a elas. É na escola que deixamos de aprender com a sabedoria da velhice e negamos o encanto das várias idades. Silenciamos o mundo dos idosos e das mulheres, assim como distorcemos ou negamos culturas de outros povos, grupos ou categorias sociais. diferentes daqueles impostos pelos livros didáticos e pela cultura da mídia" ${ }^{11}$. A escola precisa ressignificar o seu

I0. RIPPER, Afira Vianna. O preparo do professor para as novas tecnologias. 1995. Homepage: http://www.Leia.fae.unicamp.br/preparo.htm 11. OSOWSKI. Cecília Irene. Saberes pedagógicos numa perspectiva inaciana. Revista de Educação CEAP. Salvador: CEAP. ano 6, n. 20 , mar. 98, p. 64-77. 
papel, estabelecendo uma relação prazerosa entre o conhecimento e o saber.

O segundo aspecto importante, sinalizado por Tatiane, é a utilização da tecnologia na escola. Será que a discussão realizada após a exibição de uma fita de vídeo permite que o imaginário dos alunos aflorem? Que possam fazer as mais ricas e diferentes leituras do filme apresentado? Os professores que vêm interagindo com as novas tecnologias na escola já contemplam uma lógica hipertextual ${ }^{12}$, que rompe com a linearidade e a hierarquia? Ou a discussão em sala de aula segue uma única linha de raciocínio, que não permite a multiplicidade de visões de mundo? Vale lembrar a insistência com que Pierre Babin e Marie-France Kouloumdjian, já em 1983, alertaram sobre o perigo de se confundir as coisas ao introduzir o audiovisual na escola. Para eles, "a experiência mostra que, ao querermos integrar demais o audiovisual dentro dos métodos escolares, nós o matamos, fazendo do prazer um dever"13.

Como esses jovens aprendem interagindo com as máquinas? Aprendem futucando, diz Indi, sem pestanejar e manipulando o microfone com uma desconcertante espontaneidade. Aprendem com o outro, aprendem através de erros e acertos, aprendem através da leitura icônica. Enfim, aprendem interagindo com o objeto do conhecimento, sem medos, transformando e sendo transformados. E na escola, como aprendem? Na escola, diz Indi, aprendem porque têm mais tarefas. A escola resiste e proíbe, na fala destes jovens, a entrada de brinquedos como o bate-bate, tamagotchis e a simples bola de futebol, porque estes elementos podem desestruturar a sua pseudo-organização. A palavra de ordem é disciplina. O mais interessante neste aspecto é a postura ambivalente que esses jovens adotam frente às decisões da escola. Questionam mas acham que é desta forma que tem que ser. Observem o diálogo entre uma repórter que cobria o evento e Osvaldo (Ticó):

- Na sua escola tem computador, estas coisas?

- Tem não.

- Você acha que faz falta para

o que você vem aprendendo na escola?

- Não, porque quem tem escola não depende disso, acho que quem gosta de aprender não depende destas coisas.

- Você acha então que o professor, o quadro e o giz são suficientes?

- Sim.

Esse mesmo adolescente, que aqui verbaliza uma satisfação com a prática pedagógica da escola, registra, em outro momento, que o pior da escola é a diretora. Além disso, ele afirma ter dificuldade em Matemática, sinalizando desta forma que a escola não é tão perfeita assim. Contraditório?! Não... No fundo o que se percebe é que esta pseudocontradição é o próprio resultado da atual educação escolar: de um lado o que se aprende de fato e, de outro, o discurso sobre o aprender na escola, que vale mais.

No discurso dos jovens percebe-se ainda uma clareza com relação às características marcantes da cultura tecnológica, como por exemplo o rompimento da noção de tempo e espaço e o aumento da velocidade de transmissão de mensagens por intermédio dos novos meios de comunicação, favorecendo a ubiqüidade. Para Tatiane, a Internet "vai além de uma rede ligada a muitos computadores. [São] vários internautas que trocam mensagens e idéias sobre qualquer assunto que esteja ocorrendo".

A idéia de comunicação com os outros é forte. O cartaz do evento, feito por Divonei, aluno de uma escola municipal da periferia, traz o desenho de uma criança na frente do computador

12. O termo "lógica hipertextual" está sendo utilizado como sinônimo de "lógica rizomática", referida anteriormente.

13. BABIN, Pierre, KOULOUMDJIAN, Marie-France. Os novos modos de compreender - a geraçũo do audiovisual e do computador. São Paulo: Paulinas, 1989. p. 173. 
digitando no teclado. Ao ser questionado sobre o que ele estava pensando quando fez o desenho, não vacilou: "pra eu comunicar com os outros....".

Para Claudemir, ter uma homepage é muito importante: "dá pra você se comunicar mais com as pessoas, as pessoas te conhecem mais, você aparece assim, mais né, essa coisa".

Estes depoimentos nos impõem repensar o papel da escola. Uma escola que precisa estar conectada com o mundo. Conectada fisicamente, através destas tecnologias (computadores, televisão...) mas, fundamentalmente, conectada com o mundo de forma autônoma e se transformando em um local de produção de cultura e conhecimento, articulada com o que vem acontecendo ao seu redor. Desta forma, visualizase uma possibilidade de se romper com o limitado conceito de que aprender é ficar gravado na memória.

Resumo: O artigo discute sobre a necessidade de a escola reavaliar-se enquanto espaço de produção de conhecimento, à medida que não tem atentado para as transformações que as tecnologias da comunicação operam nas novas gerações. Ter acesso às tecnologias é fato importante para a escola, pois elas estão atuando sobre as estruturas cognitivas das crianças e, portanto, requerendo do ambiente escolar alterações no tratamento das disciplinas e dos currículos, que levem em conta as novas formas de adquirir informação, para transformá-la em conhecimento de maneira prazerosa.

Palavras-chave: tecnologia, estruturas cognitivas, ambiente escolar, conhecimento, prazer
Isso nos impõe pensar numa outra escola, num outro currículo. Portanto, é essencial discutir no ambiente escolar a construção deste novo currículo que "não compactua com a tradicional organização dos conteúdos, própria das tradicionais estruturas curriculares, mas vai na direção de uma simultânea articulação vertical e transversal dos conteúdos, sem uma estrutura preestabelecida de modo rígido e que se pretenda permanente, tomando-se por base as demandas emergentes no processo de aprendizagem e construção do conhecimento, além disso, que esteja de acordo com as prioridades de cada comunidade escolar. Assim, o currículo realmente se constituirá em um espaço multirreferencial de aprendizagem" ${ }^{14}$.

Enfim, o que percebemos deste encontro é que precisamos repensar a escola, mas repensá-la como um todo, de sua arquitetura ao currículo, introduzindo uma outra lógica, não mais linear e cartesiana mas sim uma lógica hipertextual, que possibilite transformar a escola em um lugar de produção cultural e não apenas apropriação de conhecimento e cultura.

Abstract. The article discusses the need for the school to reevaluate itself as a space for the production of knowledge since it has paid no attention to the transformations the communication technologies have generated among the new generations. Having access to technology is an important fact for the school, since it is working on the children's cognitive structures and, therefore, requiring changes in the school environment, in the treatment given to the disciplines and to the curricula, so they consider new ways of obtaining information, in order to transform such information into knowledge in a pleasureful manner.

Key words: technology, cognitive structures, school environment, knowledge, pleasure 